\title{
Mental aberrations and other demographic factors influencing homicide
}

\author{
Bhattacharya $\mathbf{P}^{1}$, Chakraborty $\mathbf{P}^{2}$, Das $\mathrm{S}^{3}$, Maiti $\mathbf{R}^{4}$, Sharma $\mathbf{M}^{5}$ \\ ${ }^{1}$ Dr. Partha Bhattacharya, Assistant Professor, Department of FMT, R G Kar Medical College, Kolkata, India ${ }^{2}$ Dr. Prabir \\ Chakraborty, Associate Professor, Department of FMT, Calcutta Medical College, Calcutta, India, ${ }^{3}$ Dr. Somnath Das, \\ Associate Professor, Department of FMT, R G Kar Medical College, Kolkata, India ${ }^{4}$ Dr. Rina Maiti, Post Graduate Student, \\ Department of FMT, Hi-Tech Medical College, Bhubhaneswar, India 50r. Mukul Sharma, Post Graduate Student, \\ Department of FMT, Hi-Tech Medical College, Bhubhaneswar, India.
}

Address for Correspondence: Dr Somnath Das, Email: somnath1976@rediffmail.com

\begin{abstract}
Introduction: It has been a long search for the identification of the personality trends among the people committing homicides. The present work searches for the type of personality disorder among the homicide offenders and identify its demographic profiles in a cross-sectional study at a correctional home at Kolkata. Methods: Psychiatric examination reports and crime reports of the offenders were subjected to forensic examination. [ $n=69]$. Results: Most of the offenders were found to be male, aged more than 30 years, less educated and economically backward. While delusional beliefs were found to be primary mental aberrations among the homicides. Conclusion: Homicide offenders do have a psychopathic trait and environmental influences also have an important role to play.
\end{abstract}

Key Words: Personality trends, homicide, mental aberrations.

\section{Introduction}

One man is different from another not only in his physical appearance and structure but also in his mental status, understanding capacity, tolerance, threshold of reaction and behavior. That is why in a common circumstance of passion, we find some to stay silent and others to cheer and even some may go violent, the degree of which again varies from one person to another. Similarly in a circumstance of perceptible frustration, one may take that easily, one may be revengeful while a third person suffering from such adverse reaction may commit suicide. It is doubtless that social environment of an individual affects the behavioral pattern of a subject to a great extent. But the variability of individual reaction in similar circumstance in a given social and environmental condition may indicate that there are other factors influencing the behavior pattern of a subject and that is also very important and cannot be ignored.

According to a recent study on Finnish homicidal adolescents, approximately $50 \%$ were diagnosed as having a conduct disorder or a personality disorder,

Manuscript received: $21^{\text {st }}$ Apr 2014

Reviewed: $25^{\text {th }}$ Apr 2014

Author Corrected: $3^{\text {rd }}$ May 2014

Accepted for Publication: $7^{\text {th }}$ June 2014 while $7 \%$ of these offenders suffered from schizophrenia. Sixty-four percent of the adolescents were intoxicated by alcohol and $21 \%$ were under the influence of drugs at the time of the killing; however, as many as $32 \%$ of the offenders were considered not to suffer from a mental illness or substance abuse [1].

The aim of this study was to evaluate the mental aberrations among the homicide offenders and to compare these findings with their demographic profile, such a study in this part of the country.

\section{Materials \& Methods}

The subjects for the study were chosen from inmates of a Correctional Home at Kolkata who committed homicide in different cases. They were taken to prison as either due to the commission of the act, or the subjects were placed inside the psychiatric ward of the correctional home where act of commission of the murder was found in some way or other related with some sort of their mental unsoundness. Psychiatric examination reports and crime reports of the offenders were subjected to forensic examination. 
Exclusion criteria: Those who got acquittal due to mental unsoundness even after commission of murder and treated elsewhere or were somehow or other are at large could not be studied.

\section{Results}

Table 1: Age \& sex distribution of homicide offenders

\begin{tabular}{|l|l|}
\hline AGE $[$ Years $]$ & MALE \\
\hline$<15$ & 0 \\
\hline $15--<20$ & 2 \\
\hline $20--<30$ & 10 \\
\hline $30--<50$ & 29 \\
\hline 50 ABOVE & 28 \\
\hline Total & 69 \\
\hline
\end{tabular}

Out of the 69 subjects all were male and about $83 \%$ of the cases were above 30 years.

Table 2: Occupational data of subjects who committed homicide

\begin{tabular}{|l|l|}
\hline Profession & No. of People \\
\hline Cultivation & 20 \\
\hline Unskilled labor & 10 \\
\hline Unlawful means & 10 \\
\hline Dependant & 9 \\
\hline small business/ service & 7 \\
\hline Unemployed & 10 \\
\hline Student & 3 \\
\hline
\end{tabular}

Cultivation was the commonest occupation (20) which was followed by unskilled labor, people earning livelihood by unlawful means and unemployment. Students were least common (3).

Table 3: Educational background of subjects who committed homicide

\begin{tabular}{|l|l|l|l|}
\hline Education level & Illiterate & Basic education & Higher education \\
\hline Number of Cases & 26 & 39 & 4 \\
\hline
\end{tabular}

Illiteracy and basic education shared the major chunk of educational strata (94\%).

Table 4: Family type of the homicide offenders

\begin{tabular}{|l|l|}
\hline Joint & Unit \\
\hline 54 & 15 \\
\hline
\end{tabular}

Most of the homicide offenders were from joint family (54 in number).

Table 5: Number of the homicide offenders having some degree of mental aberration

\begin{tabular}{|l|l|}
\hline Total Cases & 69 \\
\hline Cases with mental aberrations & 34 \\
\hline
\end{tabular}

Out of the total cases, 34 showed clear cut evidence of mental aberration. 
Table 6: Distribution of different mental aberrations in homicide

\begin{tabular}{|l|l|}
\hline Mental states & Number of cases \\
\hline Manic state & 4 \\
\hline Schizophrenia & 4 \\
\hline Depressive psychosis & 4 \\
\hline Psychopath & 3 \\
\hline Emotional outburst & 5 \\
\hline Persecutory Delusion & 12 \\
\hline Mental sub normality & 2 \\
\hline Total & 34 \\
\hline
\end{tabular}

Persecutory Delusion amounted for 35\% of the mental aberration, where as Depressive psychosis, Schizophrenia and manic state shared $11 \%$ of the cases. Emotional outburst amounted for $15 \%$ of the cases, but mental sub normality were extremely rare.

Table 7: Immediate causes of precipitating homicides believed by the offenders revealed during investigation

\begin{tabular}{|l|l|}
\hline Cause & Male \\
\hline Monetary & 4 \\
\hline Sex related & 2 \\
\hline Preplanned with persecutory belief & 16 \\
\hline Impulsive & 6 \\
\hline
\end{tabular}

16 cases out of 34 had a preplan with persecutory belief during the killing, which was followed by sudden impulse and monetary causes. Only 2 cases had a sex related cause as the back ground.

\section{Discussion}

This study comprised of 69 homicides of which some of them committed more than one homicide \& some had previous history of commission of some other offences before committing homicides. Of the 69 such persons, 34 were proved to be mentally unsound by the way of medical evidences, history \& other circumstantial evidences.

In the present study no female inmate was found with history of commission of homicides. This correlation is very robust: no matter which other variables are included or excluded from the regression, we found that the female-male ratio remained highly significant, always with a negative sign [2].

Most of the study populations were aged 30 years or above which is a bit different from the studies conducted abroad where approximately a third [34\%] of murder victims and almost half [49\%] of the offenders were under age 25 [3]. This may be due to the familial and financial pressure which is really a big concern among the people of the developing country. Whereas in the developed countries, from the perspective of situational perspectives, participation in the urban illicit economy increases the likelihood that youth will be involved in violent encounters and thereby amplifies their risk of committing murder [4].

Among the cluster of explanatory predictors, the most salient were environmental and socioeconomic rather than individual factors [4]. In the present study, profession wise, a large chunk of the subjects came from lower socio-economic group which may implicate that financial problems may have relationship with both insanity \& crime of the homicides offenders. As it was identified, economic down turns increases acquisitive crime. Increases in acquisitive crime, in turn, produce increases in homicides by exposing more people to the rises of criminal life styles and to situations in which nonviolent mean of resolving disputes are un available [5].

In our study, many of these people were illiterate or were just literate or had basic education [94\%]. This suggests that a low education level combined with low socioeconomic status was responsible for insanity which was again responsible for commission of murder [6]. Hence education had some relationship with serious offences. It is established fact that poverty, rapid growth in population and mental disorders- are the influencing 
factors which led to the offences committed by the vulnerable individual [7].

Family environment and relationship was also an important factor. Most of our offenders were from a joint family. Weizmann et al found that victims of offenders with psychopathy are less often family members and more often strangers than is the case with other nonpsychopathic violent offenders [8]. However such observation was based on a group of female offenders. Most of the history reveals that some family problems were upsetting the mental condition of the subject. It is possible that the turmoil that occurs in a joint family may increase the stress up on a person which may account for their insanity or insecureness. Similarly lack of care of children in poor, large family may be responsible for childhood delinquency in which case, the subject may turn into a fully fledged criminal in future [9].

The facts that reflected from the above figures are that out of the established homicides 34, who were definitely insane they had different immediate cause for killing people, of which preplan with persecutory belief was the commonest. Persecutory belief as a common cause of murder has also been accepted by many trials abroad [10], whereas sexual homicides are a rare phenomenon.

In persecutory delusion, interfering agent may be animate or inanimate, other people or machines; may be system, organizations or institutions rather than individuals. Sometimes the patient experiences persecution as a vague influence without knowing who is responsible. May occur in conditions like: Schizophrenia, Affective psychosis: Manic, Depressive type and Organic states: Acute, chronic. Persecutory overvalued ideas are a prominent facet of the litiginous type of paranoid personality disorder [11]. Our study is no exception to some studies where paranoid delusion as a cause of murder is well established [12]. Almost one-third of the cases were suffering from Persecutory Delusion.

\section{Summary and Conclusion}

Homicide has definite relationship with commission of mental unsoundness of various types with socioeconomic $\&$ familial cases. But mentally unsound persons are more vulnerable to commit these offences though there is lack of motive or intent or desire. It was also apparent that good number of offenders tried to establish defense on the ground of insanity at the time of commission of the act though they may not be clearly insane. The theory of diminished responsibility should be taken as a reality with due consideration. Most of the precipitating causes of insanity were also the precipitating causes of homicide, incidences of which are to some extent preventable.

\section{Funding: Nil}

\section{Conflict of interest: Nil}

Permission from IRB: Yes

\section{References}

1. Hagelstam C, Häkkänen H: Adolescent homicides in Finland: offence and offender characteristics. Forensic Sci Int 2006, 164:110-115

2. Jean Dreze and Reetika Khera Crime, Gender, and Society in India: Insights from Homicide Data Population and Development Review, Vol. 26, No. 2 [Jun., 2000], pp. 335-352.

3. Cooper A, Smith EL. Homicide trends in the United States, 1980-2008. Washington, DC: Bureau of Justice Statistics, 2011.

4. David P. Farrington, Rolf Loeber and Mark T. Berg Young Men Who Kill : A Prospective Longitudinal Examination From Childhood Homicide Studies 2012 16: $99 \mathrm{http} / / / \mathrm{hsx}$. sagepub.com/content/16/2/99 . last visited on $24 / 5 / 2014$.

5. Rosenfeld, R. [2009b]. Crime is the problem: Homicide, acquisitive crime, and economic conditions. Journal of Quantitative Criminology, 25, 287-306.

6. Kerawalla, Perin C.. A Study in Indian Crime, Bombay, Popular Book Depot., 1959. (Book).

7. Paul C. Holinger, Daniel Offer, James T. Barter, and Carl C. Bell Suicide and Homicide Among Adolescents The Guliford Press [1994] pg 59.

8. Weizmann-Henelius G, Viemerö V, Eronen M: The violent female perpetrator and her victim. Forensic Sci Int 2003, 133:197-203

9. Glueck, Sheldon and Eleanor Glueck [1950], Unrevealing Juvenile Delinquency. New York: Commonwealth Fund.

10. Kellie toole, defensive homicide on trial in Victoria Monash University Law Review [vol 39, no 2] 2013 pg. 492. 
11. Chandra Kiran and Suprakash Chaudhury, Understanding delusions. Ind Psychiatry J. 2009 Jan-Jun; 18[1]: 3-18.
12. Myers WC, Monaco L., Anger experience, styles of anger expression, sadistic personality disorder, and psychopathy in juvenile sexual homicide offenders. J Forensic Sci. 2000 May;45[3]:698-701.

\section{How to cite this article?}

Bhattacharya P, Chakraborty P, Das S, Maiti R, Sharma M. Mental aberrations and other demographic factors influencing homicide. Int J Med Res Rev 2014;2(4):306- 310. doi:10.17511/ijmrr.2014.i04.08 